\title{
Prenatal diagnosis of congenital heart defects: echocardiography
}

\author{
Heather Y. Sun \\ Division of Pediatric Cardiology, Department of Pediatrics, Rady Children's Hospital, University of California, San Diego, San Diego, CA, USA \\ Correspondence to: Heather Y. Sun, MD, FASE. 3020 Children’s Way, MC 5004, San Diego, CA 92123, USA. Email: hsun@rchsd.org.
}

\begin{abstract}
Congenital heart defects (CHD) are the most common congenital anomaly, and the majority can be diagnosed during prenatal life. Prenatal detection rates remain highly variable, as most CHD occur in low risk pregnancies and therefore depend on the maternal obstetric provider to recognize fetal cardiac abnormality on obstetric screening anatomic ultrasound. Fetuses with abnormal findings on obstetric screening anatomic ultrasound and/or risk factors for cardiac disease should be referred for evaluation with fetal echocardiography. Fetal echocardiography should be performed by specialized sonographers and interpreted by physicians with knowledge of evolving fetal cardiac anatomy and physiology throughout gestation. A fetal echocardiography examination, which can be done from the late first trimester onward, utilizes a standardized and systemic approach to diagnose fetuses with CHD or other forms of primary or secondary cardiac disease. The field of fetal cardiology has advanced past the accurate prenatal diagnosis of simple and complex CHD, as fetal echocardiography enables understanding of dynamic fetal cardiac physiology and consideration of potential fetal/neonatal treatment. The greatest impact of fetal echocardiography remains identification of critical CHD before birth to allow immediate cardiac management after delivery to decrease neonatal morbidity and mortality. Analyzing the severity of abnormal cardiac physiology in various forms of CHD before birth allows the fetal cardiologist to prognosticate effects on the developing fetus, predict risk of postnatal hemodynamic instability, guide delivery planning through multidisciplinary collaboration, and anticipate how the disease will impact the neonate after delivery.
\end{abstract}

Keywords: Congenital heart defects (CHD); fetal echocardiography; fetal ultrasonography; fetal heart; prenatal diagnosis

Submitted Jul 09, 2020. Accepted for publication Aug 07, 2020.

doi: $10.21037 /$ tp-20-164

View this article at: http://dx.doi.org/10.21037/tp-20-164

\section{Introduction}

Congenital heart defects (CHD) are the most common congenital anomaly, accounting for approximately $1 \%$ of live births (1). The majority of CHD can be diagnosed during prenatal life by fetal echocardiography, which has been utilized to detect CHD in utero since $1980(2,3)$. With advances in ultrasound technology, details of fetal cardiac anatomy and physiology are able to be discerned leading to improved prenatal and perinatal management and prognostication of both simple and complex CHD (4). Prompt recognition of CHD in the fetus allows the family time to evaluate for potential associated extracardiac anomalies and/or genetic syndromes and make decisions regarding pregnancy continuation. Approximately $25 \%$ of infants with CHD have critical CHD requiring timely procedural cardiac intervention after birth to prevent significant morbidity or mortality (5). Prenatal diagnosis of critical CHD leads to appropriate prenatal multidisciplinary maternal and fetal care and delivery planning in an effort to decrease the risk of neonatal hemodynamic instability while transitioning to postnatal management in a pediatric cardiac center (4).

\section{Prenatal diagnosis of congenital heart defects}

Screening for cardiac anomalies should occur in all pregnancies during routine obstetric anatomic ultrasound examination during the second trimester (6). Some pregnancies are affected by maternal and/or fetal factors 
Table 1 Indications for fetal echocardiography

\begin{tabular}{ll}
\hline Maternal factors & Fetal factors \\
\hline - Diabetes mellitus or gestational diabetes & - Suspected cardiac anomaly on obstetric ultrasound \\
- Lupus or Sjogren's syndrome with anti-SSA/anti-SSB antibodies & - Fetal arrhythmia \\
- Use of assisted reproduction technology & - Extracardiac anomaly \\
- Maternal infection during pregnancy (i.e., Rubella, Coxsackie, Parvovirus) & - Chromosomal abnormality \\
- Teratogen exposure & - Increased NT ( $\geq 3 \mathrm{~mm})$ \\
- Phenylketonuria, uncontrolled & - Fetal hydrops or pericardial effusion \\
- Family history of congenital heart disease in $1^{\text {st }}$ degree relative & - Monochorionic twinning \\
(mother/father/sibling of fetus) & - Abnormal umbilical or placental venous anatomy
\end{tabular}

that increase the risk of fetal cardiac disease (7) and should therefore undergo fetal echocardiography regardless of obstetric anatomic ultrasound findings (Table 1). However, most CHD occurs in low risk pregnancies without maternal or fetal risk factors $(8,9)$, and therefore most referrals for fetal echocardiography and subsequent prenatal diagnosis of CHD rely solely on detection of a cardiac anomaly on screening obstetric ultrasound $(7,8)$.

Historically, obstetric anatomic ultrasound guidelines for fetal cardiac evaluation mandated only a four-chamber view, with "views of the outflow tracts attempted as part of the cardiac screening" (10). In the four-chamber view, anomalous pulmonary venous connections, atrioventricular canal defects, atrioventricular valve stenosis or atresia, Ebstein's anomaly, hypoplastic left heart syndrome (HLHS), and/or septal defects are examples of CHD that can be identified. However, many types of CHD can be missed by imaging only the four-chamber view. Outflow tract and conotruncal anomalies such as truncus arteriosus, double outlet right ventricle, D-transposition of the great arteries (d-TGA), tetralogy of Fallot (TOF), pulmonary stenosis, pulmonary atresia with intact ventricular septum, and aortic stenosis may only be detected on outflow tract imaging. In 2013, the American Institute of Ultrasound in Medicine officially recognized the importance of imaging ventricular outflow tracts by updating its guidelines on obstetric anatomic ultrasound to include these critical outflow tract views into its basic cardiac examination (6). These guidelines (developed in conjunction with the American College of Radiology, American College of Obstetricians and Gynecologists, and the Society of Radiologists in Ultrasound) are the standard of care reference for obstetric practices in the United States; similar guidelines have been published by The International Society of Ultrasound in
Obstetrics and Gynecology (11).

Despite advances in fetal cardiac imaging, prenatal detection rates of CHD remain highly variable (Table 2) (12-21). In particular, detection rates of CHD affecting the outflow tracts are particularly low $(22,23)$ as compared to other types of critical CHD which affect the four-chamber view (such as single ventricle lesions) $(12,24)$. Contemporary studies have shown a wide range of prenatal diagnosis rates for conotruncal anomalies, ranging from $25 \%$ to $75 \%$ (16-18,21,25-27). Prenatal detection rates of cardiac outflow tract anomalies have not increased significantly and remain suboptimal (28) despite the updated anatomic ultrasound guidelines in 2013.

To optimize prenatal detection of CHD, sonographers and practitioners who perform fetal anatomic screening ultrasounds must be, at a minimum, comfortable with assessing the four-chamber and ventricular outflow tract views (Figure 1) in accordance with the recommended guidelines. Studies have shown that less experienced obstetric sonographers have lower detection rates of cardiac abnormalities on screening ultrasound (29). Any concerns for a fetal cardiac abnormality raised by screening ultrasound should be directed to more comprehensive fetal echocardiography. Fetal echocardiography by fetal/pediatric cardiac sonographers, with interpretation by fetal/pediatric cardiologists, provides more accurate prenatal cardiac diagnosis $(30,31)$ as compared to obstetric ultrasound and allows for specialized prenatal parental counseling as well as delivery management in an appropriate setting (32).

\section{Current guidelines for fetal echocardiography}

The fetal heart should be assessed in all pregnancies during the standard obstetric anatomic ultrasound, typically 
Table 2 Contemporary rates of prenatal detection of select congenital heart defects

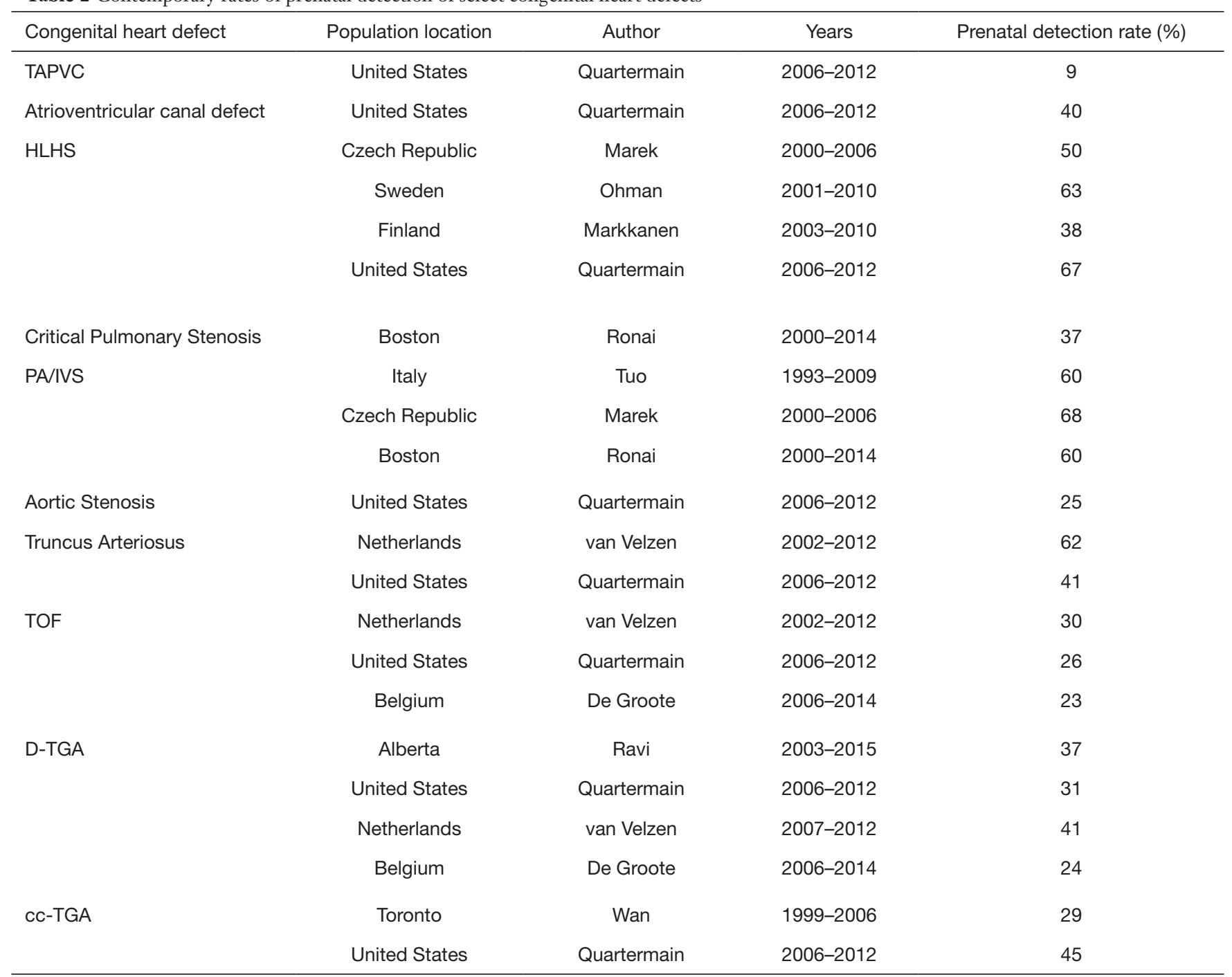

TAPVC, total anomalous pulmonary venous connection; HLHS, hypoplastic left heart syndrome; PA/IVS, pulmonary atresia/intact ventricular septum; TOF, tetralogy of Fallot; D-TGA, d-transposition of the great arteries; cc-TGA, congenitally corrected transposition of the great arteries.

performed between 18-22 weeks gestation, with adequate visualization of the four-chamber and ventricular outflow tract views (6). Any fetus with abnormal cardiac views or increased maternal or fetal risk of CHD (Table 1) should undergo detailed fetal echocardiography (7). With normal cardiac views on screening anatomic ultrasound, fetal echocardiography can still increase detection of CHD (usually non-critical) in pregnancies at higher risk than the general population (33).

\section{Performance of fetal echocardiography}

Fetal echocardiography should be performed by trained and skilled sonographers and physicians $(34,35)$ who have a detailed understanding of normal and abnormal fetal cardiac anatomy and physiology. The physician interpreting the fetal echocardiography examination should have comprehensive and contemporary knowledge of management options and outcomes of all forms of CHD, as counseling the family is an important component of 

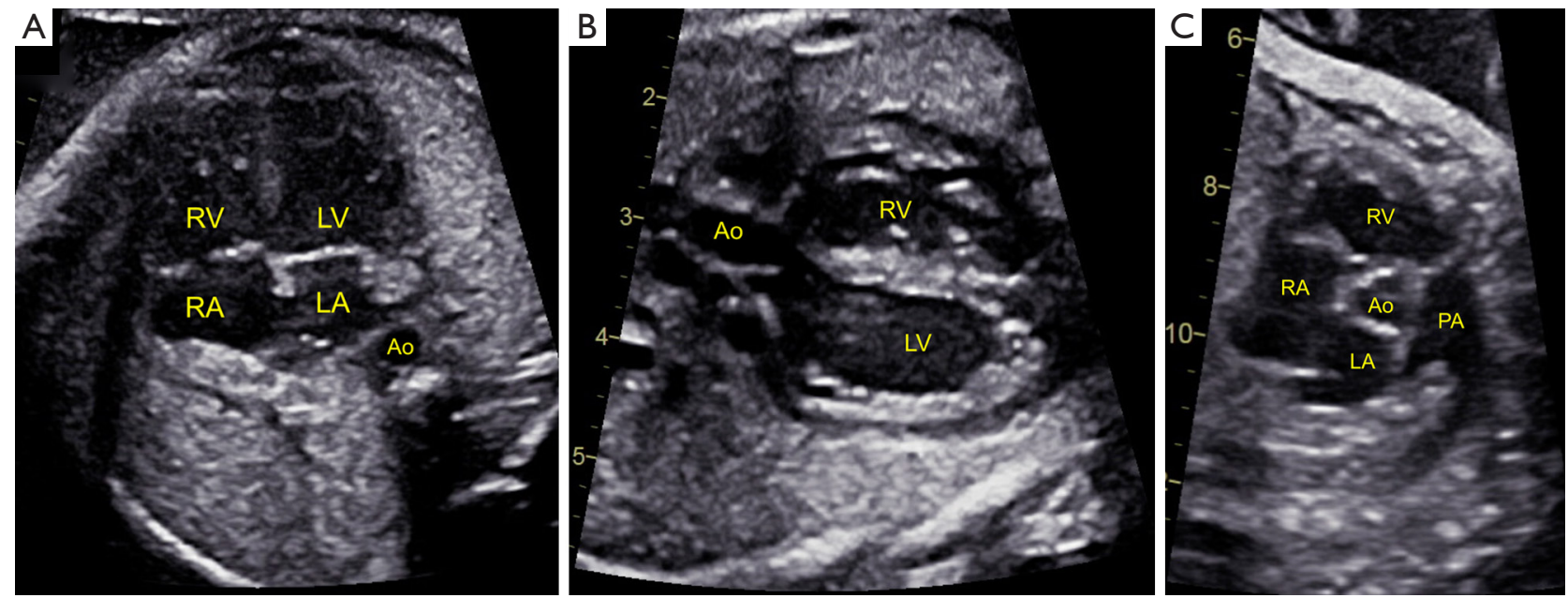

Figure 1 Cardiac screening views in routine obstetric anatomic ultrasound include the (A) four-chamber, (B) left ventricle (LV) outflow tract, and (C) right ventricle (RV) outflow tract views. RA, right atrium; LA, left atrium; PA, pulmonary artery; Ao, aorta.

caring for the fetus with CHD. The interpreting physician should also be integrated in a multidisciplinary team of fetal and pediatric care providers, such as perinatalogists, neonatologists, geneticists, pediatric cardiologists, and pediatric cardiovascular surgeons for optimal care coordination of both fetus and mother.

The optimal timing for screening fetal echocardiography is typically between 18-22 weeks gestation (36). Early fetal echocardiography (performed before 16 weeks gestation) is typically reserved for those with fetuses at highest risk of having CHD, such as increased nuchal translucency $\geq 3.5 \mathrm{~mm}$ (37), abnormal ductus venosus (38), extracardiac or genetic abnormality, prior child with significant CHD, or monochorionic twinning (39). In this subset of pregnancies at highest risk for fetal CHD, early fetal echocardiography can be performed transvaginally (40) (as early as 11 weeks gestation) or transabdominally (41) (as early as 13-14 weeks gestation) to identify CHD. While early fetal echocardiography can accurately detect major CHD (Figure 2), some defects may not be apparent or manifest until later gestation $(42,43)$. Therefore, early fetal echocardiography should supplement, but not replace, standard midgestation transabdominal fetal echocardiography (44). Fetal echocardiography should be performed as soon as possible following abnormal findings on obstetric ultrasound. It is important to note the inherent limitations of fetal cardiac imaging throughout pregnancy, as some defects may not be detected in utero, such as small atrial or ventricular septal defects, minor valvar abnormalities, partial anomalous pulmonary venous return, coronary artery anomalies, or aortic coarctation. In addition, some forms of CHD may not be detected by mid-gestation fetal echocardiography due to manifestations in later gestation, such as isolated valvar pulmonary or aortic stenosis (45), cardiomyopathy, or cardiac tumors (46).

The ultrasound system used for fetal echocardiography should be capable of two-dimensional, color and pulsewave Doppler, and M-mode imaging, with transducer probes with frequencies between 4-12 MHz. The highest frequency transducer should be utilized to maximize frame rate (with a preferred minimum of $50 \mathrm{~Hz}$ and optimum of $80-100 \mathrm{~Hz}$ ) due to the fast fetal heart rate (typically between 120-160 bpm). The fetal sonographer should be cognizant to optimize acoustic windows, which can be affected by maternal body habitus, fetal lie, and fetal movement.

A comprehensive fetal echocardiography examination utilizes a systematic approach maximizing standard views of the fetal heart to evaluate each cardiac structure from multiple planes $(11,35,47)$. The cardiac structures should be critically evaluated utilizing a combination of twodimensional or gray scale imaging with color and pulsewave Doppler interrogation. Due to the dynamic nature of cardiac structures and function, the views should be recorded with moving cine clips. Color Doppler should be used to evaluate for flow disturbances through each of the cardiac valves as well as systemic and pulmonary venous flow into and arterial flow out of the heart (48). Pulse wave spectral Doppler assessment is necessary to quantify flow 

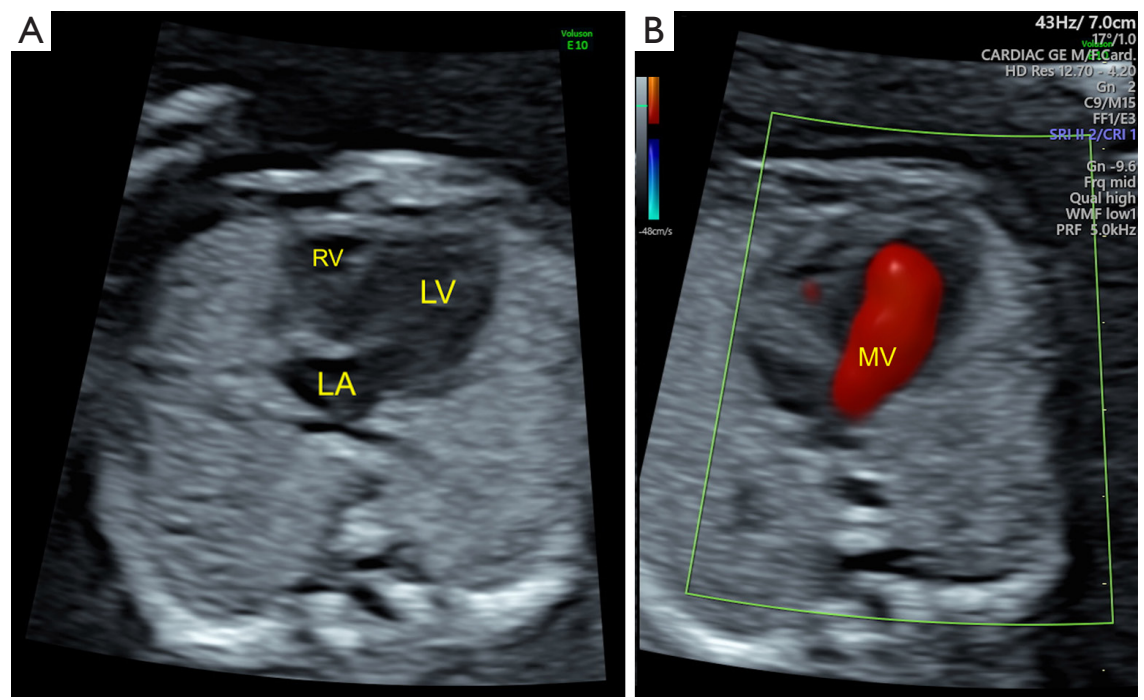

Figure 2 Early fetal echocardiography in a 15-week fetus with tricuspid atresia. (A) Four-chamber view showing hypoplastic right ventricle (RV) with normal left atrium (LA) and left ventricle (LV). (B) Absent tricuspid valve inflow and normal mitral valve (MV) inflow are demonstrated with color flow imaging.

through each valve as well as any abnormal flows detected by color Doppler. Ductus venosus and umbilical artery and vein flow are also typically assessed to monitor potential effects of altered fetal hemodynamics $(49,50)$. The fetal heart rate and rhythm should be determined by pulse wave Doppler and/or M-mode imaging. Measurements of cardiac chambers, valve annuli, and vessel dimensions in two-dimensional imaging can be referenced to normative datasets based on fetal gestational age or biometry $(51,52)$. Fetal cardiac function can be assessed qualitatively by twodimensional imaging and/or quantitatively by M-mode or advanced techniques (such as strain or tissue Doppler imaging). Biometric measurements typically include at a minimum cardiothoracic ratio and femur length.

\section{Fetal echocardiography: standard views}

The methodical use of standard two-dimensional views provides a comprehensive evaluation of mid-gestation cardiac anatomy (53). The minimum standard views include definition of visceral and cardiac situs, four-chamber, right and left ventricular outflow tracts, three-vessel, three-vessel trachea, bicaval, ductal arch, aortic arch, and short-axis of the ventricles and great arteries. Additional non-traditional planes may be necessary to define abnormal cardiac anatomic connections in fetuses with complex CHD.

Each fetal echocardiography examination should begin by establishing fetal lie followed by visceral and cardiac situs. The heart should sit in the left chest with a leftward apex, and a transverse sweep down to the abdomen should demonstrate a left sided stomach and right sided liver. In the transverse plane, the heart should comprise one third of the thoracic cavity area.

In the four-chamber view (Figure 1A), the position and size of atria and ventricles as well as the integrity of the interatrial and interventricular septum are evaluated. The foramen ovale flap is seen directing flow from the umbilical vein and should bow into the left atrium. At least one pulmonary vein from the right and one from the left lung should be seen entering the posterior wall of the left atrium. At the crux of the heart, the tricuspid valve attachment should be more apically displaced than the mitral valve attachment. The diameters of the tricuspid and mitral valve annuli (in diastole) and the right (RV) and left ventricles (LV) (at their maximal dimensions at end diastole) can be measured. The right and left side should be fairly symmetric in size. Color and pulse wave Doppler of the tricuspid and mitral inflows should show laminar flow with biphasic E and $\mathrm{A}$ waves. The moderator band should be seen in the anterior and rightward ventricle, identifying it as the true morphologic RV. In contrast, the posterior and leftward ventricle should be more smooth-walled, identifying it as the morphologic LV.

Evaluation of the outflow tracts is critical to detecting 

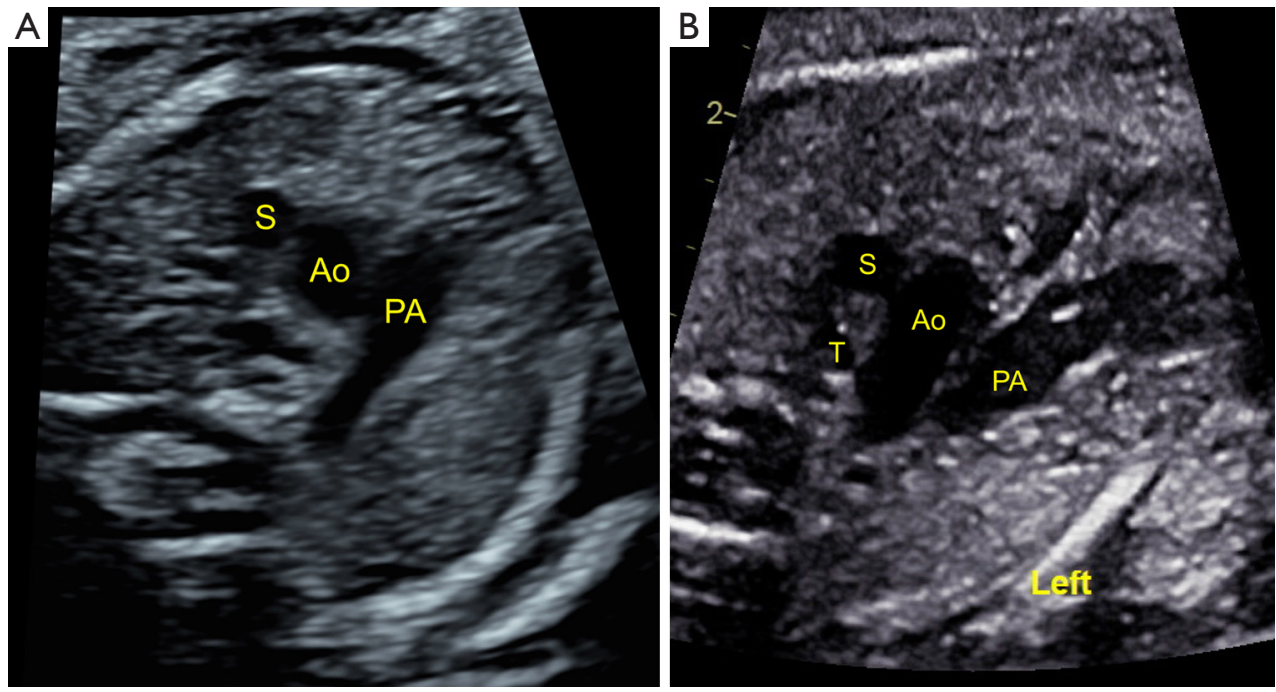

Figure 3 Normal (A) three-vessel and (B) three-vessel trachea view demonstrating a normal left-sided aortic arch. S, SVC; Ao, aorta; PA, pulmonary artery; $\mathrm{T}$, trachea.

CHD, many of which can have a normal appearing fourchamber view, such as d-TGA, TOF, and truncus arteriosus amongst many others. A sweep from the four-chamber view superiorly should demonstrate the LV outflow tract crossing perpendicular to the more anterior RV outflow tract. The ventricular septum should be intact. The $L V$ outflow tract view demonstrates the continuity of the ventricular septum with the great artery arising from it, which should not bifurcate (Figure 1B). In the RV outflow tract view, the main pulmonary artery should be seen bifurcating into the right and left branch pulmonary arteries (Figure 1C). The aortic and pulmonary valves should be assessed in a moving clip to demonstrate symmetric opening as well as with color flow and pulse wave Doppler to demonstrate normal laminar flow (with a velocity $<100 \mathrm{~cm} / \mathrm{sec}$ ).

The three-vessel view is taken cranial to the fourchamber view, with the cross-sections of the superior vena cava, aorta, and pulmonary artery forming a linear configuration (Figure 3A). The superior vena cava has the smallest caliber and is more rightward and posterior than the aorta; the aorta is smaller than the pulmonary artery, which is largest and most leftward and anterior. In the three-vessel trachea view, the aortic and ductal arches should form a "V" shape alignment leftward of the midline echogenic trachea (Figure 3B) with flow from anterior to the posterior descending aorta.

A long-axis sagittal plane towards the right demonstrates the bicaval view, with the superior vena cava and inferior vena cava joining into the right atrium. The foramen ovale flap can be seen deviating into the left atrium with flow from the umbilical vein and ductus venosus directed from the right towards the left atrium. More leftward, the ductal arch is seen arising from the short-axis of the right ventricle and directs flow from the pulmonary artery into the descending aorta. The aortic arch is more U-shaped and confirmed by demonstrating its head and neck vessel branches; the caliber of the ascending, transverse, and descending aorta should be relatively equal throughout. The short-axis view of the great arteries should show the tricuspid valve, RV outflow tract, and pulmonary artery wrapping around the shortaxis of the aortic valve (Figure 1C). The short-axis view of the ventricles should be swept from apex to base with both two-dimensional and color flow imaging to demonstrate integrity of the ventricular septum.

\section{Fetal echocardiography: advanced}

Advanced fetal echocardiography techniques can supplement and aid the prenatal diagnosis of CHD. A thorough discussion of the available imaging modalities is beyond the scope of this review article. Strain or myocardial deformation imaging tracks movement of the myocardium throughout the cardiac cycle and analyzes global or regional abnormalities in myocardial function in various fetal cardiac diseases $(54,55)$. Spectral or color tissue Doppler imaging quantifies the velocity of interrogated myocardial tissue 
throughout the cardiac cycle, also evaluating for changes in fetal cardiac function in research and clinical practice (56). Current technologies in 3D/4D fetal echocardiography enable rapid acquisition of volumetric data of the heart that can be manipulated post-acquisition for improved diagnosis and understanding of spatial relationships in CHD $(57,58)$.

\section{Fetal cardiology}

Most forms of CHD can be detected on fetal echocardiography, with some limitations as previously discussed. Several questions should be addressed upon diagnosis of a fetus with CHD: What is the risk of associated extracardiac anomalies or an underlying genetic syndrome? Are fetal cardiac interventions or in utero medical treatment options available? Is the fetus stable before birth, or is there risk of progressive heart failure and fetal demise? Will the family pursue pregnancy termination, cardiac intervention, or palliative care? After delivery, will the neonate be at high risk of hemodynamic decompensation upon separation from the maternal-placental circulation? What specialists need to be involved with the delivery and immediate postnatal care of the neonate? What postnatal cardiac interventions are anticipated? Addressing each type of CHD and its prenatal implications is outside the scope of this review, but select examples and the impact of prenatal diagnosis on perinatal and neonatal management will be highlighted here.

The prenatal diagnosis of CHD should prompt a thorough evaluation for extracardiac anomalies or genetic syndrome in the fetus. Fetuses can have associated malformations of or secondary developmental effects on the brain, lungs, kidneys, gastrointestinal and/or genitourinary systems which can impact perinatal morbidity as well as affect postnatal management. Genetic abnormalities have been found in up to $50 \%$ of fetuses with CHD (59), with certain types associated with higher risk of genetic abnormality (i.e., Atrioventricular canal defect with Trisomy 21 or truncus arteriosus, TOF, interrupted aortic arch, or right aortic arch with $22 \mathrm{q} 11$ deletion). Due to the association with genetic syndromes, all mothers of fetuses prenatally diagnosed with CHD should undergo consideration of genetic counseling and additional testing (i.e., amniocentesis with karyotyping or microarray).

Fetal cardiac intervention in a small subset of fetuses with CHD may be considered in an effort to alter natural in utero course, increase postnatal treatment options, and improve long-term outcomes (60-62). For example, a subset of mid-gestation fetuses with critical aortic stenosis may evolve to develop HLHS by the end of gestation (63). Fetal balloon aortic valvuloplasty can relieve the aortic valve stenosis, promote flow through and potential growth of the left heart structures, and enable possibility of a biventricular circulation after birth (64) (Figure 4). Similarly, fetal balloon pulmonary valvuloplasty may be considered in a subset of mid-gestation fetuses with critical pulmonary stenosis or pulmonary atresia who may develop significant right heart hypoplasia without intervention $(65,66)$. Families should be counseled that although fetal cardiac intervention may be technically successful (67), controversy exists weighing the risks versus benefits to the mother and fetus (68), who may or may not ultimately be a candidate for biventricular palliation after birth. Follow-up fetal echocardiography after intervention evaluates the impact on cardiac structural growth and physiology and provides up-to-date counseling regarding potential postnatal management and outcomes to the family.

Serial fetal echocardiography throughout gestation monitors for progressive fetal cardiac disease and the development of fetal heart failure. CHD at risk for fetal heart failure includes abnormal valves at risk for increasing valvar regurgitation or valvar stenosis, progressive obstructive lesions with risk for myocardial dysfunction, and structural abnormalities with risk for developing arrhythmias or heart block. Fetal heart failure can lead to valvar regurgitation, cardiomegaly, increased central venous pressure, and ultimately impede umbilical venous flow causing fetal hydrops with high risk of intrauterine demise (69). Assessment of the cardiovascular profile score by fetal echocardiography can be used to monitor fetuses at risk (49), with a low score predicting perinatal mortality. Options for transplacental medical therapy are limited in fetuses with structural or myocardial cardiac disease. Transplacental digoxin has been shown to improve heart failure, demonstrated by improved cardiovascular profile scores, in a small number of heterogeneous cases (70). In fetuses with Ebstein's anomaly or tricuspid valve dysplasia with circular shunt physiology due to significant tricuspid and pulmonary regurgitation, transplacental indomethacin and ibuprofen can cause ductal constriction, to diminish pulmonary regurgitation and systemic steal, prolong gestation, and increase perinatal survival $(71,72)$. More successful treatment options exist for fetuses with arrhythmias, who may be given transplacental or more direct injections of antiarrhythmics (73). The decision regarding whether the presence of hydrops should prompt premature delivery should be weighed carefully against the 

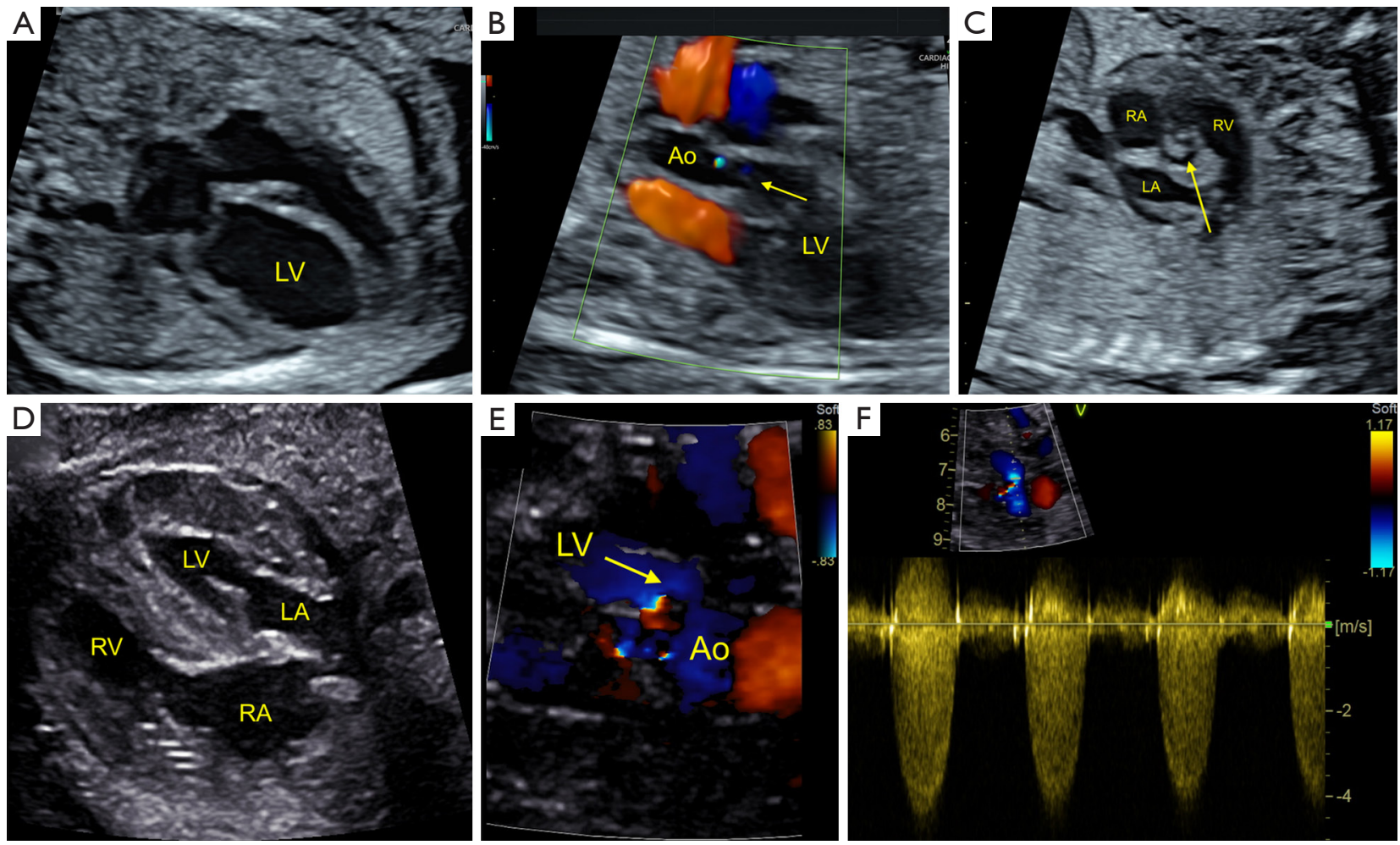

Figure 4 Fetus with critical aortic stenosis and evolving HLHS physiology at (A) 19 weeks gestation, with a dilated left ventricle (LV) with endocardial fibroelastosis and (B) minimal antegrade flow (arrow) across a (C) severely dysplastic and stenotic aortic valve. (D) After fetal balloon aortic valvuloplasty, the LV is hypertrophied with normalized function and (E) improved flow (arrow) across the (F) stenotic aortic valve at 34 weeks gestation. This infant subsequently required balloon aortic valvuloplasty in the neonatal period. Ao, aorta; RA, right atrium; LA, left atrium; RV, right ventricle.

known risks of prematurity associated with poor outcomes in major CHD (74).

Fetal echocardiography can guide delivery planning, as infants with critical CHD can have significant cyanosis, hypoxemia, and/or cardiogenic shock leading to morbidity/ mortality after birth if not expeditiously treated. Fetuses can be stratified by risk of post-delivery hemodynamic compromise and need for urgent intervention upon separation from the maternal-placental circulation (32). For example, infants with total anomalous pulmonary venous connection (TAPVC) can manifest clinically with significant cyanosis and hypoxemia after delivery (75). While it can occur in isolation, TAPVC associated with other forms of critical CHD (such as heterotaxy) (Figure $5 A$ ) is more likely to be diagnosed prenatally (75). The low rate of prenatal diagnosis in isolated TAPVC is likely due to its more subtle appearance on screening cardiac views. Fetuses with obstructed TAPVC identified by fetal echocardiography (Figure 5B) are at high risk of significant hypoxemia after birth without rapid cardiac intervention and should therefore undergo coordinated (with possible C-section) delivery to ensure prompt access to pediatric cardiology and cardiovascular surgery (76).

Prenatal detection improves pre-operative morbidity, mortality, and outcomes in certain types of CHD, such as d-TGA and HLHS (77-79). The majority of fetuses with d-TGA (Figure 6) remain stable in utero, supported by the placental circulation. After delivery, newborns with d-TGA can quickly become cyanotic and may require urgent balloon atrial septostomy to ensure adequate mixing between the parallel deoxygenated and oxygenated circulations. All fetuses with d-TGA are considered to be at high risk of hemodynamic decompensation after delivery and should prompt discussions to consider coordination of delivery close to a pediatric cardiac care center. Certain echocardiographic findings of abnormal septum primum, highly restrictive/intact atrial septum, and/or abnormal ductus arteriosus flow $(80,81)$ in fetuses with d-TGA 

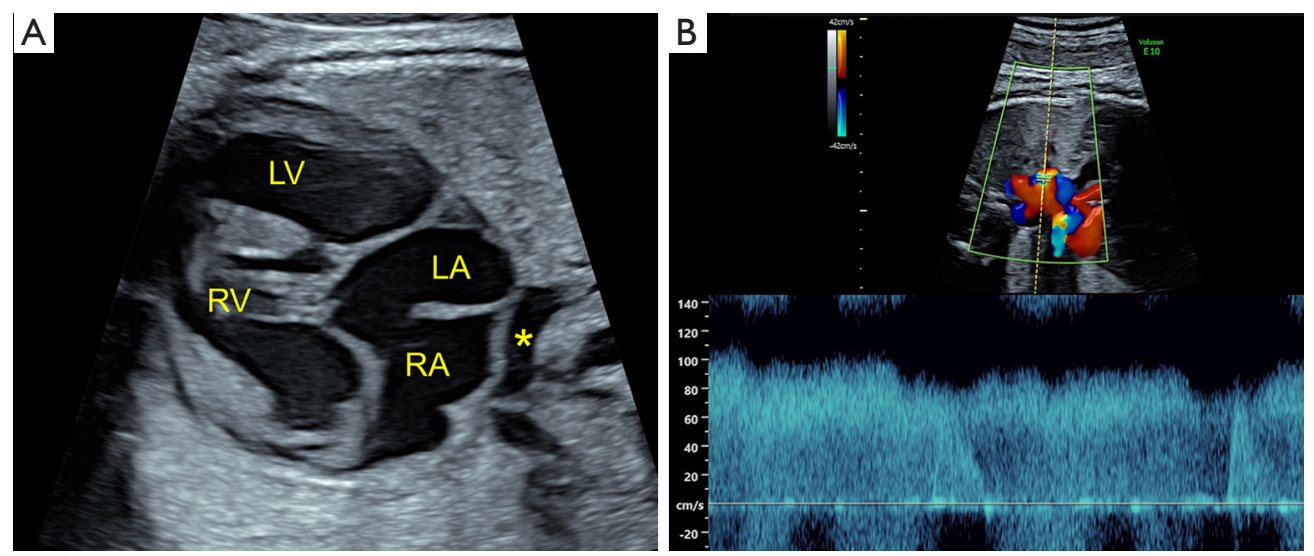

Figure 5 Total anomalous pulmonary venous connection in a fetus with heterotaxy, atrioventricular canal defect, and pulmonary stenosis. (A) The pulmonary venous confluence $\left(^{*}\right)$ is seen behind the right (RA) and left atrium (LA). (B) Pulse wave Doppler of the vertical vein showing non-phasic high velocity flow, consistent with obstruction, as it enters the innominate vein. RV, right ventricle; LV, left ventricle.
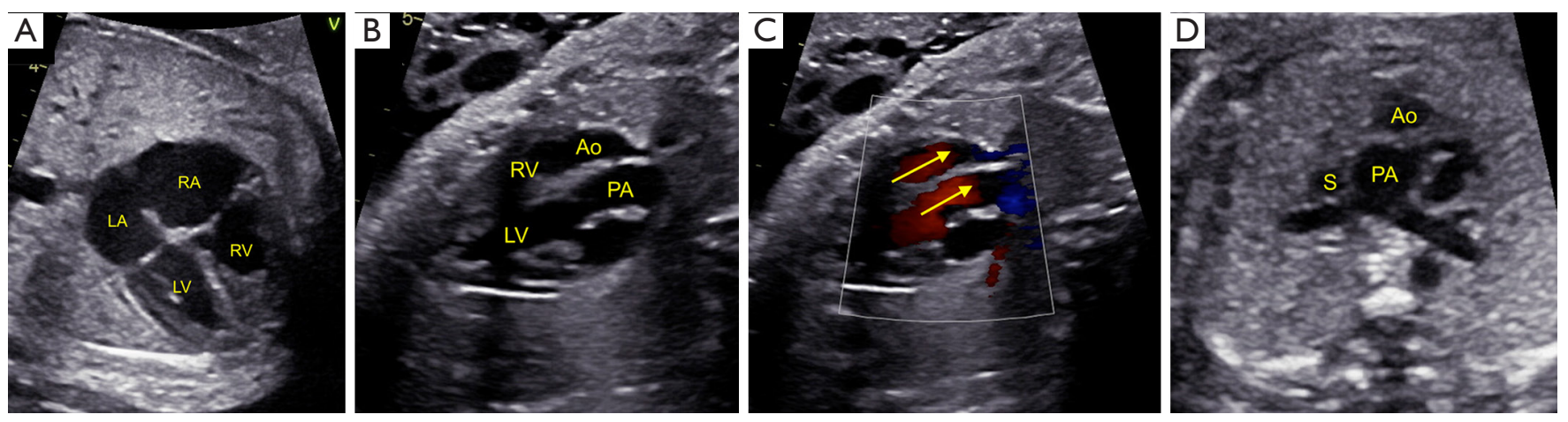

Figure 6 (A) Normal appearing four-chamber view in a fetus with D-transposition of the great arteries. (B) Abnormal parallel outflow tracts (arrows) are shown in two dimensional and (C) color flow imaging, with the right ventricle (RV) connected to the aorta (Ao) and the left ventricle (LV) connected to the pulmonary artery (PA). (D) Abnormal three-vessel view with the aorta anterior to the pulmonary artery. RA, right atrium; LA, left atrium; S, superior vena cava.

predict need for urgent balloon atrial septostomy. Similarly, in fetuses with HLHS, some develop restrictive or intact atrial septum impeding the return of oxygenated pulmonary venous blood flow causing severe hypoxemia after birth (82). Foramen ovale flow (Figure $7 A$ ) and pulmonary venous Doppler assessment (Figure $7 B$ ) can risk stratify these fetuses, with significant pulmonary venous flow reversal predicting need for urgent atrial septostomy after birth $(83,84)$. HLHS fetuses with atrial restriction and significant pulmonary venous obstruction have worse outcomes $(85,86)$ and survival (87) due to secondary effects on developing pulmonary vasculature (88). These findings in utero should guide medical team decision making regarding delivery (89) and parental desire for surgical versus palliative care postnatally.

Some fetuses with CHD remain stable in utero with lower risk for hemodynamic compromise if ductal patency is maintained after birth (with the use of prostaglandin infusion) to preserve adequate pulmonary or systemic blood flow. Fetuses with right heart obstructive lesions, such as critical pulmonary stenosis, pulmonary atresia, severe TOF, or tricuspid stenosis/atresia with restrictive pulmonary flow, require a patent ductus arteriosus for pulmonary blood flow to prevent severe cyanosis after birth. The presence of fetal left to right (aorta to pulmonary) flow in the ductus arteriosus (instead of its normal flow from the pulmonary artery to descending aorta) predicts postnatal ductal dependency in right heart lesions (90) (Figure 8). 

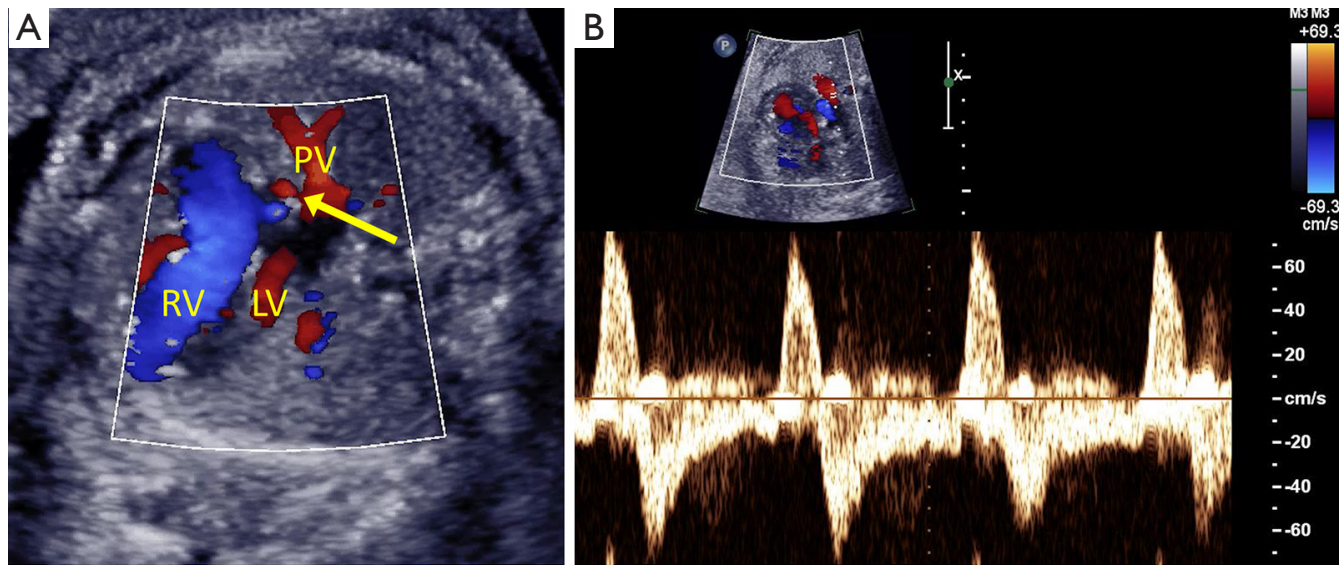

Figure 7 Fetus with hypoplastic left heart syndrome and (A) restrictive atrial septum (arrow), causing pulmonary vein (PV) flow reversal. (B) PV pulse wave Doppler shows significant A wave reversal (above the baseline). RV, right ventricle; LV, left ventricle.
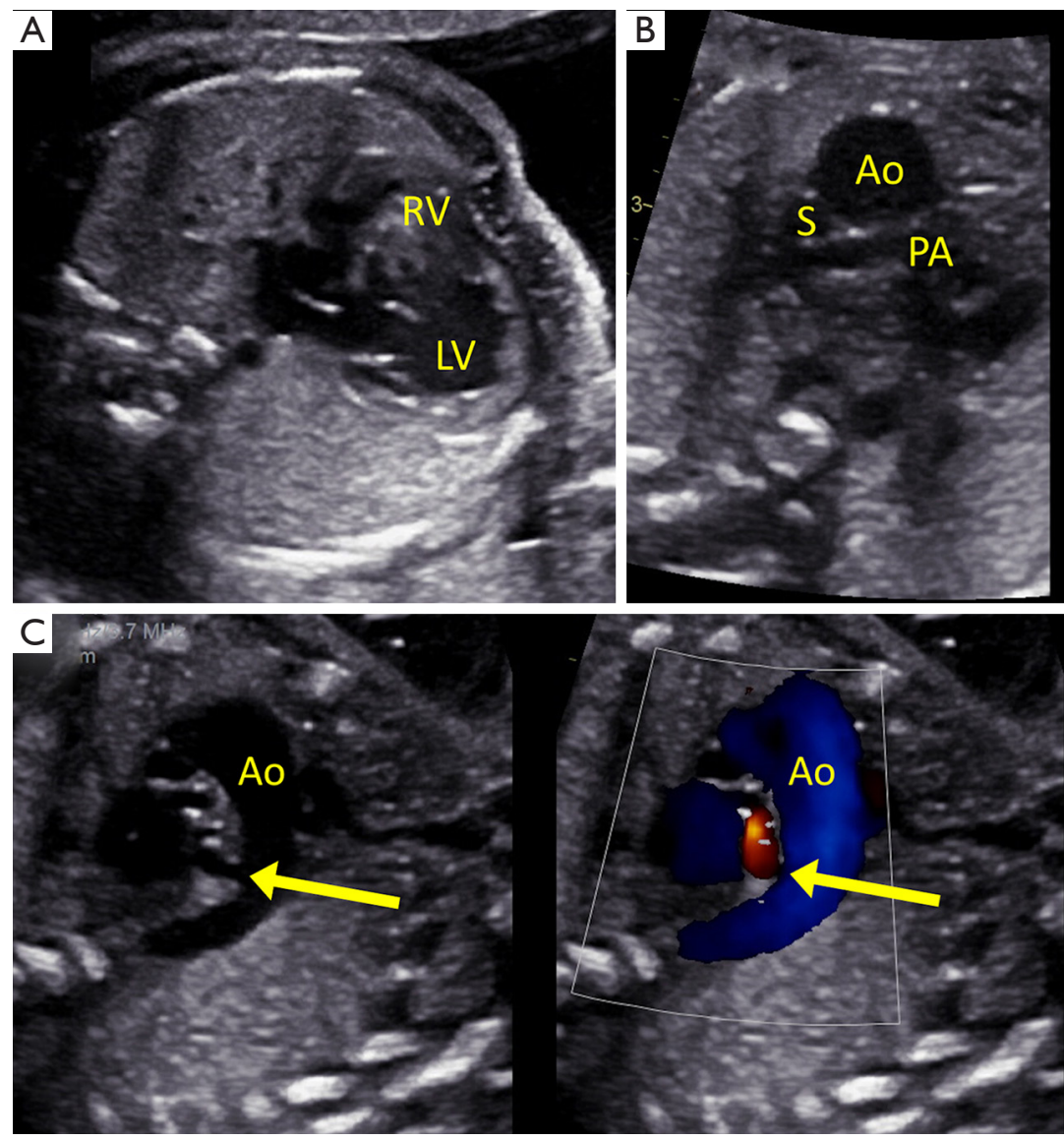

Figure 8 Fetus with pulmonary atresia and intact ventricular septum. (A) The right ventricle (RV) is severely hypoplastic and hypertrophied compared to the dilated left ventricle (LV). (B) Abnormal three-vessel view demonstrating a dilated aorta (Ao) and small pulmonary artery (PA). (C) Reverse oriented (arrow) ductus arteriosus with aorta to pulmonary artery flow predicting neonatal ductal dependence for pulmonary blood flow. S, superior vena cava. 

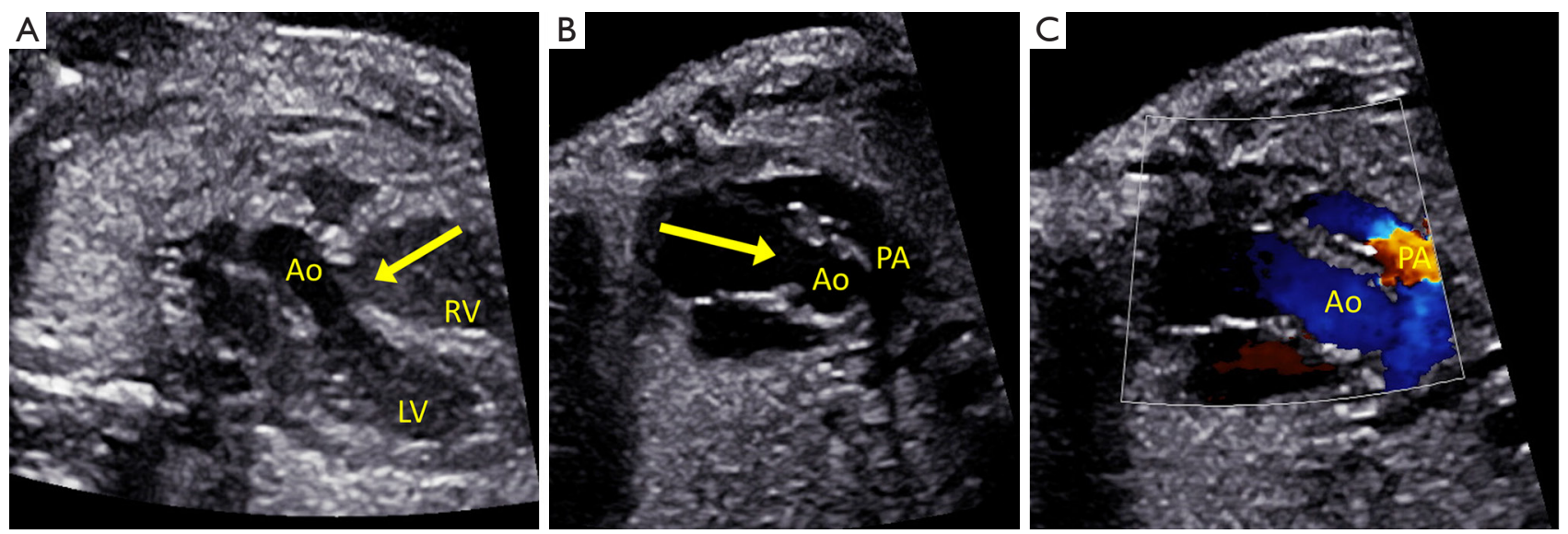

Figure 9 Fetus with non-ductal dependent tetralogy of Fallot. (A) Outflow tract imaging showing the overriding aorta (Ao) and ventricular septal defect (arrow). (B) Short axis view of the aorta and anterior malalignment ventricular septal defect (arrow), with the pulmonary artery (PA) smaller than the aorta. (C) Color flow shows mild flow acceleration across the mildly hypoplastic pulmonary valve.

Fetuses with left heart obstructive lesions, such as HLHS, critical aortic stenosis, aortic coarctation, or interrupted aortic arch, require a patent ductus arteriosus to maintain systemic perfusion after birth to prevent cardiogenic shock. Abnormal left to right flow across the foramen ovale predicts ductal dependent left sided CHD $(91,92)$. Fetuses with aortic arch obstruction may have normal right to left flow across the foramen ovale, and determining true ductal dependence in fetuses with suspected aortic coarctation can be challenging by fetal echocardiography (93). Delivery planning for infants with ductal dependent CHD should consider their proximity to and need for admission to pediatric cardiac care centers with cardiac catheterization and surgical services.

Fetuses with minimal risk for ductal dependency or neonatal intervention can be safely delivered without alterations to planned location. Newborns with shunt lesions (i.e., isolated ventricular septal defects, balanced atrioventricular canal defects) or mild forms of TOF (Figure 9) typically remain hemodynamically stable in utero and can be evaluated with non-urgent/outpatient pediatric cardiology follow-up after delivery. These families benefit from prenatal counseling and anticipation of postnatal cardiac course, but can be reassured that the likelihood of neonatal cardiac intervention is low.

\section{Conclusions}

Fetal echocardiography plays an integral role in the accurate prenatal diagnosis of $\mathrm{CHD}$, and the demonstration of cardiac physiology in utero guides collaborative maternal and fetal care. The biggest limitation to the prenatal diagnosis of CHD remains its reliance on obstetrical providers to identify affected or at-risk pregnancies and therefore continued efforts in education should focus on these primary care sonographers and providers. When prenatal diagnosis of CHD is achieved, continuity of care for these families is established before birth, with the fetal cardiologist laying the foundation to guide the family and to optimize short and long-term outcomes.

\section{Acknowledgments}

Funding: None.

\section{Footnote}

Provenance and Peer Review: This article was commissioned by the Guest Editor (Antonio F. Corno) for the series "Prenatal Diagnosis in Congenital Heart Defects" published in Translational Pediatrics. The article has undergone external peer review.

Conflicts of Interest: The author has completed the ICMJE uniform disclosure form (available at http:// dx.doi.org/10.21037/tp-20-164). The series "Prenatal Diagnosis in Congenital Heart Defects" was commissioned by the editorial office without any funding or sponsorship. The author has no other conflicts of interest to declare. 
Ethical Statement: The author is accountable for all aspects of the work in ensuring that questions related to the accuracy or integrity of any part of the work are appropriately investigated and resolved.

Open Access Statement: This is an Open Access article distributed in accordance with the Creative Commons Attribution-NonCommercial-NoDerivs 4.0 International License (CC BY-NC-ND 4.0), which permits the noncommercial replication and distribution of the article with the strict proviso that no changes or edits are made and the original work is properly cited (including links to both the formal publication through the relevant DOI and the license). See: https://creativecommons.org/licenses/by-nc-nd/4.0/.

\section{References}

1. Hoffman JI, Kaplan S. The incidence of congenital heart disease. J Am Coll Cardiol 2002;39:1890-900.

2. Lange LW, Sahn DJ, Allen HD, et al. Qualitative real-time cross-sectional echocardiographic imaging of the human fetus during the second half of pregnancy. Circulation 1980;62:799-806.

3. Kleinman CS, Hobbins JC, Jaffe CC, et al. Echocardiographic studies of the human fetus: prenatal diagnosis of congenital heart disease and cardiac dysrhythmias. Pediatrics 1980;65:1059-67.

4. Berkley EM, Goens MB, Karr S, et al. Utility of fetal echocardiography in postnatal management of infants with prenatally diagnosed congenital heart disease. Prenat Diagn 2009;29:654-8.

5. Oster ME, Lee KA, Honein MA, et al. Temporal trends in survival among infants with critical congenital heart defects. Pediatrics 2013;131:e1502-8.

6. American Institute of Ultrasound in Medicine. AIUM practice guideline for the performance of obstetric ultrasound examinations. J Ultrasound Med 2013;32:1083-101.

7. Donofrio MT, Moon-Grady AJ, Hornberger LK, et al. Diagnosis and treatment of fetal cardiac disease: a scientific statement from the American Heart Association. Circulation 2014;129:2183-242.

8. Stümpflen I, Stumpflen A, Wimmer M, et al. Effect of detailed fetal echocardiography as part of routine prenatal ultrasonographic screening on detection of congenital heart disease. Lancet 1996;348:854-7.

9. Simpson LL. Indications for fetal echocardiography from a tertiary-care obstetric sonography practice. J Clin
Ultrasound 2004;32:123-8.

10. International Society of Ultrasound in Obstetrics \& Gynecology. Cardiac screening examination of the fetus: guidelines for performing the 'basic' and 'extended basic' cardiac scan. Ultrasound Obstet Gynecol 2006;27:107-13.

11. Carvalho JS, Allan LD, Chaoui R, et al. ISUOG Practice Guidelines (updated): sonographic screening examination of the fetal heart. Ultrasound Obstet Gynecol 2013;41:348-59.

12. Quartermain MD, Pasquali SK, Hill KD, et al. Variation in Prenatal Diagnosis of Congenital Heart Disease in Infants. Pediatrics 2015;136:e378-85.

13. Öhman A, El-Segaier M, Bergman G, et al. Changing Epidemiology of Hypoplastic Left Heart Syndrome: Results of a National Swedish Cohort Study. J Am Heart Assoc 2019;8:e010893.

14. Markkanen HK, Pihkala JI, Salminen JT, et al. Prenatal diagnosis improves the postnatal cardiac function in a population-based cohort of infants with hypoplastic left heart syndrome. J Am Soc Echocardiogr 2013;26:1073-9.

15. Ronai C, Freud LR, Brown DW, et al. Low prenatal detection rate of valvar pulmonary stenosis: What are we missing? Prenat Diagn 2020;40:966-71.

16. Tuo G, Volpe P, Bondanza S, et al. Impact of prenatal diagnosis on outcome of pulmonary atresia and intact ventricular septum. J Matern Fetal Neonatal Med 2012;25:669-74.

17. Marek J, Tomek V, Skovranek J, et al. Prenatal ultrasound screening of congenital heart disease in an unselected national population: a 21-year experience. Heart 2011;97:124-30.

18. van Velzen CL, Clur SA, Rijlaarsdam ME, et al. Prenatal detection of congenital heart disease--results of a national screening programme. BJOG 2016;123:400-7.

19. Ravi P, Mills L, Fruitman D, et al. Population trends in prenatal detection of transposition of great arteries: impact of obstetric screening ultrasound guidelines. Ultrasound Obstet Gynecol 2018;51:659-64.

20. De Groote K, Vanhie E, Roets E, et al. Outcome after prenatal and postnatal diagnosis of complex congenital heart defects and the influence of genetic anomalies. Prenat Diagn 2017;37:983-91.

21. Wan AW, Jevremovic A, Selamet Tierney ES, et al. Comparison of impact of prenatal versus postnatal diagnosis of congenitally corrected transposition of the great arteries. Am J Cardiol 2009;104:1276-9.

22. Levy DJ, Pretorius DH, Rothman A, et al. Improved prenatal detection of congenital heart disease in 
an integrated health care system. Pediatr Cardiol 2013;34:670-9.

23. Sklansky MS, Berman DP, Pruetz JD, et al. Prenatal screening for major congenital heart disease: superiority of outflow tracts over the 4-chamber view. J Ultrasound Med 2009;28:889-99.

24. Friedberg MK, Silverman NH, Moon-Grady AJ, et al. Prenatal detection of congenital heart disease. J Pediatr 2009;155:26-31, 31.e1.

25. Swanson TM, Selamet Tierney ES, Tworetzky W, et al. Truncus arteriosus: diagnostic accuracy, outcomes, and impact of prenatal diagnosis. Pediatr Cardiol 2009;30:256-61.

26. Khoshnood B, Lelong N, Houyel L, et al. Impact of prenatal diagnosis on survival of newborns with four congenital heart defects: a prospective, population-based cohort study in France (the EPICARD Study). BMJ Open 2017;7:e018285.

27. Lara DA, Fixler DE, Ethen MK, et al. Prenatal diagnosis, hospital characteristics, and mortality in transposition of the great arteries. Birth Defects Res A Clin Mol Teratol 2016;106:739-48.

28. Sun HY, Proudfoot JA, McCandless RT. Prenatal detection of critical cardiac outflow tract anomalies remains suboptimal despite revised obstetrical imaging guidelines. Congenit Heart Dis 2018;13:748-56.

29. Tegnander E, Eik-Nes SH. The examiner's ultrasound experience has a significant impact on the detection rate of congenital heart defects at the second-trimester fetal examination. Ultrasound Obstet Gynecol 2006;28:8-14.

30. Meyer-Wittkopf M, Cooper S, Sholler G. Correlation between fetal cardiac diagnosis by obstetric and pediatric cardiologist sonographers and comparison with postnatal findings. Ultrasound Obstet Gynecol 2001;17:392-7.

31. Lai CW, Chau AK, Lee CP. Comparing the accuracy of obstetric sonography and fetal echocardiography during pediatric cardiology consultation in the prenatal diagnosis of congenital heart disease. J Obstet Gynaecol Res 2016;42:166-71.

32. Donofrio MT, Levy RJ, Schuette JJ, et al. Specialized delivery room planning for fetuses with critical congenital heart disease. Am J Cardiol 2013;111:737-47.

33. Cawyer CR, Kuper SG, Ausbeck E, et al. The added value of screening fetal echocardiography after normal cardiac views on a detailed ultrasound. Prenat Diagn 2019;39:1148-54.

34. Quiñones MA, Douglas PS, Foster E, et al. ACC/AHA clinical competence statement on echocardiography: a report of the American College of Cardiology/ American Heart Association/American College of Physicians-American Society of Internal Medicine Task Force on clinical competence. J Am Soc Echocardiogr 2003;16:379-402.

35. Rychik J, Ayres N, Cuneo B, et al. American Society of Echocardiography guidelines and standards for performance of the fetal echocardiogram. J Am Soc Echocardiogr 2004;17:803-10.

36. Allan LD. Cardiac anatomy screening: what is the best time for screening in pregnancy? Curr Opin Obstet Gynecol 2003;15:143-6.

37. Zosmer N, Souter VL, Chan CS, et al. Early diagnosis of major cardiac defects in chromosomally normal fetuses with increased nuchal translucency. Br J Obstet Gynaecol 1999;106:829-33.

38. Martínez JM, Comas M, Borrell A, et al. Abnormal firsttrimester ductus venosus blood flow: a marker of cardiac defects in fetuses with normal karyotype and nuchal translucency. Ultrasound Obstet Gynecol 2010;35:267-72.

39. Campbell KH, Copel JA, Ozan Bahtiyar M. Congenital heart defects in twin gestations. Minerva Ginecol 2009;61:239-44.

40. Johnson P, Sharland G, Maxwell D, et al. The role of transvaginal sonography in the early detection of congenital heart disease. Ultrasound Obstet Gynecol 1992;2:248-51.

41. Carvalho JS, Moscoso G, Ville Y. First-trimester transabdominal fetal echocardiography. Lancet 1998;351:1023-7.

42. Simpsom JM, Jones A, Callaghan N, et al. Accuray and limitations of transabdominal fetal echocardiography at 12-15 weeks of gestation in a population at high risk for congenital heart disease. BJOG 2000;107:1492-7.

43. Moon-Grady A, Shahanavaz S, Brook M, et al. Can a complete fetal echocardiogram be performed at 12 to 16 weeks' gestation? J Am Soc Echocardiogr 2012;25:1342-52.

44. Yagel S, Cohen SM, Messing B. First and early second trimester fetal heart screening. Curr Opin Obstet Gynecol 2007;19:183-90.

45. Freud LR, Moon-Grady A, Escobar-Diaz MC, et al. Low rate of prenatal diagnosis among neonates with critical aortic stenosis: insight into the natural history in utero. Ultrasound Obstet Gynecol 2015;45:326-32.

46. Chao AS, Chao A, Wang TH, et al. Outcome of antenatally diagnosed cardiac rhabdomyoma: case series and a meta-analysis. Ultrasound Obstet Gynecol 2008;31:289-95. 
47. AIUM Practice Parameter for the Performance of Fetal Echocardiography. J Ultrasound Med 2020;39:E5-E16.

48. Sharland GK, Chita SK, Allan LD. The use of colour Doppler in fetal echocardiography. Int J Cardiol 1990;28:229-36.

49. Wieczorek A, Hernandez-Robles J, Ewing L, et al. Prediction of outcome of fetal congenital heart disease using a cardiovascular profile score. Ultrasound Obstet Gynecol 2008;31:284-8.

50. Bianco K, Small M, Julien S, et al. Second-trimester ductus venosus measurement and adverse perinatal outcome in fetuses with congenital heart disease. J Ultrasound Med 2006;25:979-82; quiz 983.

51. Schneider C, McCrindle BW, Carvalho JS, et al. Development of Z-scores for fetal cardiac dimensions from echocardiography. Ultrasound Obstet Gynecol. 2005;26:599-605.

52. Pasquini L, Mellander M, Seale A, et al. Z-scores of the fetal aortic isthmus and duct: an aid to assessing arch hypoplasia. Ultrasound Obstet Gynecol 2007;29:628-33.

53. Picazo-Angelin B, Zabala-Arguelles JI, Anderson RH, et al. Anatomy of the normal fetal heart: The basis for understanding fetal echocardiography. Ann Pediatr Cardiol 2018;11:164-73.

54. Cohen J, Binka E, Woldu K, et al. Myocardial strain abnormalities in fetuses with pulmonary atresia and intact ventricular septum. Ultrasound Obstet Gynecol 2019;53:512-9.

55. Truong UT, Sun HY, Tacy TA. Myocardial deformation in the fetal single ventricle. J Am Soc Echocardiogr 2013;26:57-63.

56. Comas M, Crispi F. Assessment of fetal cardiac function using tissue Doppler techniques. Fetal Diagn Ther 2012;32:30-8.

57. DeVore GR, Satou G, Sklansky M. 4D fetal echocardiography-An update. Echocardiography 2017;34:1788-98.

58. Yagel S, Cohen SM, Rosenak D, et al. Added value of three-/four-dimensional ultrasound in offline analysis and diagnosis of congenital heart disease. Ultrasound Obstet Gynecol 2011;37:432-7.

59. Paladini D, Calabro R, Palmieri S, et al. Prenatal diagnosis of congenital heart disease and fetal karyotyping. Obstet Gynecol 1993;81:679-82.

60. Freud LR, Tworetzky W. Fetal interventions for congenital heart disease. Curr Opin Pediatr 2016;28:156-62.

61. Allan LD. Rationale for and current status of prenatal cardiac intervention. Early Hum Dev 2012;88:287-90.
62. McElhinney DB, Tworetzky W, Lock JE. Current status of fetal cardiac intervention. Circulation 2010;121:1256-63.

63. McElhinney DB, Marshall AC, Wilkins-Haug LE, et al. Predictors of technical success and postnatal biventricular outcome after in utero aortic valvuloplasty for aortic stenosis with evolving hypoplastic left heart syndrome. Circulation 2009;120:1482-90.

64. Freud LR, McElhinney DB, Marshall AC, et al. Fetal aortic valvuloplasty for evolving hypoplastic left heart syndrome: postnatal outcomes of the first 100 patients. Circulation 2014;130:638-45.

65. Tulzer A, Arzt W, Gitter R, et al. Immediate effects and outcome of in-utero pulmonary valvuloplasty in fetuses with pulmonary atresia with intact ventricular septum or critical pulmonary stenosis. Ultrasound Obstet Gynecol 2018;52:230-7.

66. Tworetzky W, McElhinney DB, Marx GR, et al. In utero valvuloplasty for pulmonary atresia with hypoplastic right ventricle: techniques and outcomes. Pediatrics 2009;124:e510-8.

67. Moon-Grady AJ, Morris SA, Belfort M, et al. International Fetal Cardiac Intervention Registry: A Worldwide Collaborative Description and Preliminary Outcomes. J Am Coll Cardiol 2015;66:388-99.

68. Edwards LA, Justino H, Morris SA, et al. Controversy About a High-Risk and Innovative Fetal Cardiac Intervention. Pediatrics 2018;142:e20173595.

69. Huhta JC. Guidelines for the evaluation of heart failure in the fetus with or without hydrops. Pediatr Cardiol 2004;25:274-86.

70. Patel D, Cuneo B, Viesca R, et al. Digoxin for the treatment of fetal congestive heart failure with sinus rhythm assessed by cardiovascular profile score. J Matern Fetal Neonatal Med 2008;21:477-82.

71. Torigoe T, Mawad W, Seed M, et al. Treatment of fetal circular shunt with non-steroidal anti-inflammatory drugs. Ultrasound Obstet Gynecol 2019;53:841-6.

72. Freud L, Wilkins-Haug LE, Beroukhim RS, et al. Prenatal NSAID Therapy to Mitigate Circular Shunt Physiology in Fetuses with Severe Ebstein Anomaly. Circulation 2018;138:A14979.

73. Jaeggi ET, Carvalho JS, De Groot E, et al. Comparison of transplacental treatment of fetal supraventricular tachyarrhythmias with digoxin, flecainide, and sotalol: results of a nonrandomized multicenter study. Circulation 2011;124:1747-54.

74. Costello JM, Pasquali SK, Jacobs JP, et al. Gestational age at birth and outcomes after neonatal cardiac surgery: an 
analysis of the Society of Thoracic Surgeons Congenital Heart Surgery Database. Circulation 2014;129:2511-7.

75. Domadia S, Kumar SR, Votava-Smith JK, et al. Neonatal Outcomes in Total Anomalous Pulmonary Venous Return: The Role of Prenatal Diagnosis and Pulmonary Venous Obstruction. Pediatr Cardiol 2018;39:1346-54.

76. Donofrio MT. Predicting the Future: Delivery Room Planning of Congenital Heart Disease Diagnosed by Fetal Echocardiography. Am J Perinatol 2018;35:549-52.

77. Chakraborty A, Gorla SR, Swaminathan S. Impact of prenatal diagnosis of complex congenital heart disease on neonatal and infant morbidity and mortality. Prenat Diagn 2018;38:958-63.

78. Cloete E, Bloomfield FH, Sadler L, et al. Antenatal Detection of Treatable Critical Congenital Heart Disease Is Associated with Lower Morbidity and Mortality. J Pediatr 2019;204:66-70.

79. Holland BJ, Myers JA, Woods CR, Jr. Prenatal diagnosis of critical congenital heart disease reduces risk of death from cardiovascular compromise prior to planned neonatal cardiac surgery: a meta-analysis. Ultrasound Obstet Gynecol 2015;45:631-8.

80. Punn R, Silverman NH. Fetal predictors of urgent balloon atrial septostomy in neonates with complete transposition. J Am Soc Echocardiogr 2011;24:425-30.

81. Jouannic JM, Gavard L, Fermont L, et al. Sensitivity and specificity of prenatal features of physiological shunts to predict neonatal clinical status in transposition of the great arteries. Circulation 2004;110:1743-6.

82. Rychik J, Rome JJ, Collins MH, et al. The hypoplastic left heart syndrome with intact atrial septum: atrial morphology, pulmonary vascular histopathology and outcome. J Am Coll Cardiol 1999;34:554-60.

83. Michelfelder E, Gomez C, Border W, et al. Predictive value of fetal pulmonary venous flow patterns in identifying the need for atrial septoplasty in the newborn with hypoplastic left ventricle. Circulation 2005;112:2974-9.

84. Taketazu M, Barrea C, Smallhorn JF, et al. Intrauterine pulmonary venous flow and restrictive foramen ovale in fetal hypoplastic left heart syndrome. J Am Coll Cardiol 2004;43:1902-7.

85. Vlahos AP, Lock JE, McElhinney DB, et al. Hypoplastic left heart syndrome with intact or highly restrictive atrial septum: outcome after neonatal transcatheter atrial septostomy. Circulation 2004;109:2326-30.

86. Hoque T, Richmond M, Vincent JA, et al. Current outcomes of hypoplastic left heart syndrome with restrictive atrial septum: a single-center experience. Pediatr Cardiol 2013;34:1181-9.

87. Lowenthal A, Kipps AK, Brook MM, et al. Prenatal diagnosis of atrial restriction in hypoplastic left heart syndrome is associated with decreased 2-year survival. Prenat Diagn 2012;32:485-90.

88. Graziano JN, Heidelberger KP, Ensing GJ, et al. The influence of a restrictive atrial septal defect on pulmonary vascular morphology in patients with hypoplastic left heart syndrome. Pediatr Cardiol 2002;23:146-51.

89. Sathanandam SK, Philip R, Gamboa D, et al. Management of hypoplastic left heart syndrome with intact atrial septum: a two-centre experience. Cardiol Young 2016;26:1072-81.

90. Arya B, Levasseur SM, Woldu K, et al. Fetal echocardiographic measurements and the need for neonatal surgical intervention in Tetralogy of Fallot. Pediatr Cardiol 2014;35:810-6.

91. Berning RA, Silverman NH, Villegas M, et al. Reversed shunting across the ductus arteriosus or atrial septum in utero heralds severe congenital heart disease. J Am Coll Cardiol 1996;27:481-6.

92. Edwards LA, Arunamata A, Maskatia SA, et al. Fetal Echocardiographic Parameters and Surgical Outcomes in Congenital Left-Sided Cardiac Lesions. Pediatr Cardiol 2019;40:1304-13.

93. Matsui H, Mellander M, Roughton M, et al. Morphological and physiological predictors of fetal aortic coarctation. Circulation 2008;118:1793-801.
Cite this article as: Sun HY. Prenatal diagnosis of congenital heart defects: echocardiography. Transl Pediatr 2021;10(8):2210-2224. doi: 10.21037/tp-20-164 